\title{
Współcześni Indianie Ojibway Impresje z wyjazdu do Kanady
}

Kiedy latem 2016 roku razem z Magdą Bernat oraz Kamilem Szproncelem - po raz pierwszy ruszałem w pozaeuropejski teren badawczy, zupełnie nie wiedziałem, czego się spodziewać ${ }^{1}$ Jedno było pewne: wiedzieliśmy, że zależy nam na jak najpełniejszym doświadczeniu terenu, a także obserwacji nas samych w relacji z Innym. Tylko na ile Indianie w Ontario wciąż jeszcze odróżniają się od innych mieszkańców? Jak duży wpływ na ich rdzenną kulturę wywarła amerykańska kultura popularna? Na szczęście mieliśmy niezwykłych, będących ogromnym wsparciem gospodarzy i dobrego odźwiernego, który przybliżył nam specyfikę ludu Anishinaabe (Ojibway), jak sami siebie nazywają rdzenni mieszkańcy okolicy jeziora Superior (Waldman 2006: 66).

Nasz wyjazd można podzielić na dwie części: oficjalną, polegającą na odbywaniu umówionych wcześniej spotkań za pośrednictwem naszego odźwiernego, oraz nieoficjalną, w której pogłębialiśmy nawiązane wcześniej kontakty, posługując się obserwacją uczestniczącą. Część oficjalna umożliwiła nam zdobycie ogólnej wiedzy o regionie, ludziach i tym, na jakim wizerunku własnej społeczności im zależy. Mieliśmy też okazję poznać motywy kryjące się za działaniami różnych

\footnotetext{
${ }^{1}$ Był to pierwszy pozaeuropejski wyjazd naukowy studentów etnologii z Uniwersytetu Gdańskiego. Obejmował pobyt głównie wśród Indian Ojibway w Kanadzie (London, Sudbury, Sault Ste. Marie wraz z rezerwatem Garden River oraz Wikwemikong na wyspie Manitoulin Island). Wyjazd odbył się w lipcu i sierpniu 2016 roku dzięki wsparciu oraz kierownictwu prof. dr. hab. Wojciecha Bębna. Zespół studencki stanowili Magdalena Bernat, Kamil Szproncel i Jakub Kozak. Szczególne podziękowania należą się mieszkającym na miejscu prof. Józefowi Niesyto, Jarosławowi Lazorykowi i Januszowi Kamińskiemu za niezwykłą gościnność, zaangażowanie, przewodnictwo i wsparcie merytoryczne.
} 
walczących na rzecz Indian organizacji. Natomiast uczestniczenie w codzienności i życiu domowym Indian pozwoliło nam zrozumieć trapiące ich problemy, a także poznać, jak się kształtują relacje między nimi samymi.

\section{Autentyczne, nieautentyczne...?}

Jednym z pierwszych Indian, z którymi przyszło nam nawiązać kontakt, był elder Leo mieszkający w rezerwacie Garden River. Określeniem „elder" nazywa się każdego, kto posiadł mądrość życiową (Sault 1996). Zazwyczaj są to starcy, lecz definicja nie wyklucza osób młodych. Istotne jest to, że elderem nie można się mianować, tylko rozpoznaje go społeczność. Chwila, w której inni zaczynają przychodzić do kogoś po rady i nauki, jest momentem, w którym taki człowiek staje się elderem.

Z Leo spotkaliśmy się niemal natychmiast po zakwaterowaniu w Sault Ste. Marie. Chodziliśmy na spacery, w czasie których zbieraliśmy kamienie oraz zioła do ceremonii. Wówczas uczył nas medycyny lasu, opowiadał historie o duchach, a także pokazywał święte miejsca (góra Trap Rock). Razem z elderem Leo stworzyliśmy własny ceremonialny bęben i fajkę, a także uczestniczyliśmy w rytuale sweat lodge, czyli szałasie potów. Polega on na zebraniu się w ciasnym i niskim namiocie, $\mathrm{w}$ którego centrum umieszczane są rozgrzane $\mathrm{w}$ ogniu kamienie. Następnie polewa się je wodą, tworząc kłęby pary, w której jak w saunie pocą się uczestnicy ceremonii. Wydarzenie to ma charakter sakralny i oczyszczający, a w jego trakcie można podzielić się z innymi uczestnikami trapiącymi nas problemami. $Z$ tego powodu bywa nazywany indiańską formą spowiedzi.

Elder Leo już od początku budził w nas, jako badaczach, pewne wątpliwości. Po pierwsze, ze względu na jego włoskie pochodzenie. Odkąd przynależność indiańska zaczęła przynosić wymierne korzyści (możliwość mieszkania $\mathrm{w}$ rezerwacie, dotacje i programy rządowe, specjalne prawa, np. do wyrobu tradycyjnego rzemiosła, połowu ryb), stała się ona przedmiotem prawnej ewaluacji i można się było o nią ubiegać. Każda indiańska społeczność w odpowiedzi na to wykształciła swoje reguły dostępu. Jedne są bardzo restrykcyjne, wymagające potwierdzenia indiańskiego pochodzenia, natomiast inne są niezwykle swobodne: wystarczy jedynie ogłosić, że czuje się bliskość z tradycjami danego ludu (Zimmerman 2003: 10-11).

Drugim elementem, który nas zastanawiał, była komercyjność. Nasz odźwierny dał się poznać jako osoba, która umie odpowiednio wycenić swój czas. Oprócz tego, że razem z małżonką sprzedawał swoje rękodzieło, prowadził też dla wszystkich zainteresowanych rodzaj aktywnych spacerów, które zwał Medicine Walk. $\mathrm{W}$ ich trakcie dzielił się indiańską kulturą z białymi. Na jednym z takich spotkań, na którym byliśmy, zjawiło się wiele kobiet związanych $z$ ruchem New Age, a Leo w swojej specyficznej czapce z trzema sterczącymi zeń piórami z nieskrywaną przyjemnością wchodził w rolę mistrza i oczarowywał je 
opowieściami o magii skał i roślin. Nie walczył o zrozumienie czy szacunek dla tradycji, wyglądał raczej, jakby szukał poklasku.

Kwestia udostępniania wierzeń i zwyczajów indiańskich Europejczykom jest obszernym i kontrowersyjnym tematem, który uznaliśmy za bardzo ważne zagadnienie do dalszych badań. Część Indian zachowuje bardzo restrykcyjne stanowisko i twierdzi, że to, co indiańskie, powinno być praktykowane wyłącznie przez Indian i tylko w kontekście ich kultury oraz ziemi, natomiast inni zwyczajnie dostrzegli rosnącą podaż i postanowili wykorzystać okazję.

Na sposób gospodarowania wiedzą starszyzny wpływa również słabnące zainteresowanie tradycją wśród samych Indian. Młodzi ludzie nierzadko wybierają naukę programowania czy biotechnologii zamiast dawnych mądrości. Brak następców zmusił wielu elderów do otwarcia się na każdego, kto poprosi o wiedzę, a nawet do aktywnego szukania słuchaczy (np. podczas festiwalów Pow-Wow). Niektórzy, przeczuwając nadchodzącą śmierć, zdecydowali się spisać swoją wiedzę (co jest dość odważne, bo zgodnie z tradycją święte mądrości powinno się przekazywać ustnie). Jednym z takich elderów był nieżyjący już Cal Sault, którego maszynopis mieliśmy możliwość przestudiować.

Kolejnym zaskoczeniem było też to, że elder Leo zdawał się nie traktować niczego poważnie, również swoich rytuałów. Nieustannie żartował, wszystkie czynności wykonywał bardzo swobodnie, a podczas ceremonii sweat lodge nie czuło się jej sakralnego charakteru. Rozminięcie się oczekiwań z rzeczywistością wytłumaczyliśmy sobie tak, że dla Indian sacrum przenika się z profanum, wszystko ma swojego ducha (nawet alkoholizm, bo o to też pytaliśmy), więc święta jest więc codzienność i święte są żarty. Teoria potwierdziła się, kiedy Magda została zaproszona na świętą ceremonię Women Circle. Można by się spodziewać, że towarzyszyć jej będą duchowe przeżycia, a w praktyce okazało się, że to po prostu okazja do poplotkowania między kobietami.

\section{Tradycja ciągle żywa}

Przekonanie o świętości otaczającego świata oraz swobodne i pogodne podejście do tej świętości przejawiali także inni rozmówcy. Wiara we wsparcie dobrych duchów, cykliczność życia i połączenie wszystkiego ze wszystkim nadawała egzystencji niezwykle pogodny wymiar. Doświadczyliśmy tego, odwiedzając eldera Williarda, który będąc wówczas w stanie żałoby, ciągle jeszcze współbiesiadował ze swoją zmarłą siostrzenicą, dzieląc się z nią posiłkiem przez wsypywanie jej porcji do ogniska. Jej dusza była wciąż obecna wśród nich, w wiecznym teraz. Jeden z Indian powiedział nawet, że jeśli nowo narodzone dziecko wcześnie umrze, to jego dusza zostanie przy rodzinie i wcieli się w kolejne, które się urodzi, dlatego - logicznie wnioskując - aborcja nie jest aż tak wielkim problemem.

Uniwersalnym symbolem, mitologiczną mapą opisującą indiańską rzeczywistość, jest tzw. medicine wheel, które tłumaczy się różnorako, od dosłownego: Koło Medycyny, po bardzo wyszukane: Krąg Życia. Przedstawia ono cykliczność 
czasu podzieloną na cztery etapy. Może je rozumieć na wiele sposobów: jako pory roku czy dnia, etapy życia ludzkiego, ale również symbolicznie - jako składowe rzeczywistości, takie jak żywioły, cztery kolory skóry czy cztery elementy składające się na człowieka: duch, emocje, ciało i umysł (Sault 1996).

O tym, jak żywa jest nadal ta symbolika, przekonaliśmy się w czasie wizyty w Dan Pine's Healing Lodge, znajdującym się na terenie rezerwatu Garden River. Był to bazujący na Kole Życia ośrodek pomocy i odnowy fizycznej, mentalnej, duchowej i emocjonalnej, założony przez uzdrowiciela i człowieka mocy Dana Pine'a w wyniku inspiracji snem wizyjnym. Wspomnianą kosmologię odzwierciedlała nawet jego fizyczna struktura: wybudowano go na planie koła z czterema głównymi izbami, w centrum umieszczając palenisko - ogień jako kolejny święty symbol, połączenie ziemi z niebem, a człowieka z Wielkim Duchem, odpowiednik axis mundi (kanadyjskie przepisy zabroniły palenia otwartego ognia na posadzce w budynku, więc stworzono tam piecyk, jednak, aby zachować symbolikę łączenia ziemi z niebem, i tak poza budynkiem palono normalne ognisko).

Ogień jest jednym z najsilniejszych symboli badanych Indian. Zachowała się tradycja palenia świętego ognia podczas festiwali Pow-Wow, a także instytucja firekeepera - opiekuna tego ognia. Podobnie tradycja przetrwał obyczaj przekazywania modlitw Wielkiemu Duchowi przez sypnięcie odrobiny tytoniu w ogień. Zachowało się także wiele innych rytuałów, które opisuje Basil Johnston (1990), $n p$. Vision Quest - kilkudniowe wyjście na świętą ziemię, by pościć i medytować w oczekiwaniu na wizję swojego powołania (na górze Trap Rock widzieliśmy ślady obozowania, jak również małe ofiary z błyszczących przedmiotów składane lokalnym duchom zwanym little people). W czasie rozmowy z elderem Williardem otrzymaliśmy indiańskie imiona oraz tzw. medicine bags - święte zawiniątka. Znaleźliśmy też domniemane ślady po ceremonii Sundance oraz ludzi twierdzących, że ją przechodzili.

Wszystkie te drobne gesty i obserwacje potwierdzały to, że kultura indiańska wciąż jest niezwykle żywa. Zmienia się jej otoczka materialna, natomiast warstwa symboliczna pozostaje ta sama. Jako przykłady zmian wymienić można włączenie elementów plastikowych do tradycyjnych strojów tanecznych, korzystanie z kleju i gotowych prefabrykatów, a także narzędzi elektrycznych podczas wyrabiania świętych bębnów i fajek czy zastąpienie owoców cukierkami podczas ceremonii sweat lodge. Usłyszeliśmy też historię o tym, jak uczestnicy pogrzebu zamiast polać trumnę wodą użyli do tego coca-coli, ponieważ zmarły bardzo ją lubił.

Indianie $\mathrm{w}$ naszym regionie nie zastanawiali się, czy to, co robią, spełnia jakieś z góry ustalone normy, po prostu płynęli zgodnie z prądem kulturowej zmiany. Jeśli tak jest wygodniej i łatwiej, to dlaczego tego nie wykorzystać? To może być czynnik odgrywający znaczącą rolę w przyjmowaniu konsumpcyjnych przyzwyczajeń Europejczyków. 


\section{Ciemna strona asymilacji}

Niestety jako Europejczycy „wzbogaciliśmy” indiańską kulturę nie tylko o coca-colę czy plastikowe kubeczki. Nasza ingerencja zintensyfikowała problemy nadużywania alkoholu, narkotyków, rozbicie rodzin, bezrobocie, choroby (cukrzyca, rak) i fale samobójstw. Te trudności życiowe są teraz, zaraz obok problemów ekologicznych, głównymi wyzwaniami, z którymi się zmagają Indianie. Ponadto ich tradycyjny tryb życia zdecydowanie nie sprzyja ani punktualności (Indian time - przyjdziesz, kiedy poczujesz, że teraz jest na to czas), ani pracy osiem godzin dziennie, ani roztropnemu prowadzeniu finansów. Tę trudną sytuację społeczno-gospodarczą opisali nam przedstawiciele ośrodków pomocy Indianom, wspomnianego Healing Lodge, ale też Indian Friendship Center wspierającego Indian miastowych w Sault Ste. Marie.

Z kolei podczas wizyty w Martyrs' Shrine oraz Huronia Museum w Midland mogliśmy prześledzić historyczne procesy kolonizacji i chrystianizacji, które niejako zapoczątkowały tę falę problemów. Szczególnie żywa w sercach Indian jest uraza za tzw. residential schools, szkoły zaprojektowane przez kolonizatorów z myślą o przyspieszeniu asymilacji. W praktyce cierpiało i umierało w nich wiele dzieci, siłą zabranych z plemienia i odizolowanych od rodzinnej kultury (Schmalz 1991). Przymusowa asymilacja rozbijała tożsamości młodych Indian jeszcze na przełomie XIX i XX wieku, a jedna ze sprzedających pamiątki staruszek powiedziała mi, że te szkoły działały również za jej życia. Niestety nie chciała kontynuować tego tematu. Nawet tak zdałoby się błahe rzeczy jak sprzedawane na tych straganach koszulki, młodzieżowe naszywki czy przypinki opowiadały historię dumy i tożsamości indiańskiej, budowanej często w opozycji do białego oprawcy.

Postawa roszczeniowa (nawet jeśli uzasadniona) wobec Kanadyjczyków spotyka się z próbami zadośćuczynienia od strony rządu, jednak są one nieskuteczne, za co w dużej mierze odpowiada brak zrozumienia specyfiki kultury indiańskiej. Rząd w zdecydowanej większości przypadków jedynie wypłaca pieniądze, czym tylko podtrzymuje bezrobocie, rozbicie społeczne, uzależnienia, niesamodzielność oraz wiarę w poczucie wyższości białych względem Indian.

Są jednak ludzie, którzy postanowili wziąć sprawy w swoje ręce. Aspiracją Paula Syrette'a, chiefa rezerwatu Garden River, jest rozwinięcie lokalnego przemysłu (tak właśnie powiedział), turystyki i innych usług, aby stworzyć miejsca pracy, doprowadzając tym samym do ekonomicznej wydolności i niezależności rezerwatów. Tymczasem wielu Indian nie jest jeszcze gotowych na przyjęcie idącej za tym zmiany stylu życia, a koncepcja industrializacji spotyka się z oporem motywowanym wiarą w świętość natury. 


\section{Lord Vader w pióropuszu}

Optymizmu dodaje fakt, że wskutek różnorakich starań, działalności ośrodków pomocy i silnych społecznych aktywistów oraz przede wszystkim dzięki dobrej woli i chęci dialogu powstaje coraz więcej miejsc, w których ludzie nauczyli się współpracować i z powodzeniem funkcjonują na styku dwóch kultur. Jednym z nich jest kościół katolicki w Wikwemikong, niezwykle barwny zakątek, gdzie przed wejściem stoi totem przedstawiający Trójcę Świętą, podczas mszy korzysta się z grzechotek i bębenków, na ścianach wiszą łapacze snów, a kapłan na ornacie ma namalowane Koło Życia i orlim piórem rozdmuchuje dym z kadzidełka, w którym palą się święte, indiańskie zioła.

Drugim z takich miejsc był dom indiańskiej rodziny, z którą udało nam się spędzić więcej czasu. Choć wydawało się, że żyją i mieszkają tak jak my, już od progu nieustannie zaskakiwały nas mniej lub bardziej subtelne różnice. Nikt nie przyszedł nas powitać, nie zaproponował herbaty, nie wskazał krzeseł, żeby usiąść... staliśmy w progu i nie wiedzieliśmy, co ze sobą zrobić, aż w końcu pojęliśmy, że oczekuje się od nas, że sami poczujemy się jak u siebie. Doświadczyliśmy na własnej skórze, że dzięki zetknięciu z innym człowiek uzyskuje dystans do zachowania właściwego w jego własnej kulturze, dostrzega, że to tylko jeden $\mathrm{z}$ wielu sposobów bycia w świecie, wcale nie jedyny słuszny.

Kolejnym zaskoczeniem był stopień nieuporządkowania panujący $\mathrm{w}$ domu, czym nikt się zupełnie nie przejmował. Podczas gdy w Polsce gospodynie często przepraszają za najmniejszą drobinkę kurzu, tutaj dopiero na wyraźną prośbę, że brakuje miejsca na stole, przełożono górę rzeczy $\mathrm{z}$ jednego miejsca $\mathrm{w}$ drugie. W kuchni, żeby coś przygotować do jedzenia (nie zatroszczono się o nasze wyżywienie w sposób, w jaki oczekiwałoby się tego od polskiego gospodarza), musieliśmy położyć deskę do krojenia na szczycie innej góry rzeczy, bo nie było nawet gdzie tego wszystkiego przenosić.

Naczyń praktycznie się nie myło, tylko korzystało się z plastikowych. $\mathrm{Na}$ środku kuchni stał ogromny kosz na śmieci. Wrzucało się do niego wszystko, łącznie z plastikiem i kubeczkami po kawie, którą nagminnie pito $\mathrm{w}$ jednej z popularnych sieci barów i kawiarni. Mimo deklarowanego nastawienia proekologicznego zdawało się, że „nasi” Indianie nie zdawali się jeszcze rozumieć lub nie respektować faktu, że produkcja i konsumpcja plastiku szkodzi planecie. Ważne było dla nich to, co tanie i wygodne.

Swoboda panująca $\mathrm{w}$ domu była niezwykła. Ludzie, znajomi i rodzina wchodzili i wychodzili bez żadnego powitania, każdy robił to, na co miał ochotę i nic nikomu nie przeszkadzało. Pamiętam obraz chłopaka grającego w gry wideo, którego zobaczyliśmy pierwszy raz w życiu, i który tylko na moment podniósł na nas wzrok, po czym wrócił do grania, zupełnie się nami nie zainteresowawszy.

Byliśmy też świadkami tego, jak Indianie z wielką pasją i zaangażowaniem oglądali jakiś popularnonaukowy program o duchach. Gry wideo, telewizja oraz wszelkie nowinki technologiczne bardzo szybko zdobyły nieodporne, indiańskie 
serca. Symbolem tego, jak popkultura wkradła się do domów Indian, zostanie dla mnie stojąca $\mathrm{w}$ salonie wielka figura Lorda Vadera $\mathrm{z}$ indiańskim pióropuszem na głowie.

\section{Literatura}

Johnston, B. (1990). Ojibway Ceremonies. Lincoln: University of Nebraska Press.

Sault, C. (1996). I can, I want, I will. Hagersville, Ontario: maszynopis.

Schmalz, P.S. (1991). The Ojibwa of southern Ontario. Toronto: University of Toronto Press.

Waldman, C. (2006). Encyclopedia of Native American Tribes. Wydanie 3. New York: Infobase Publishing.

Zimmerman, L.J., Molyneaux B.L. (2003). Indianie Ameryki Pótnocnej. Dzieje i plemiona. Wierzenia i rytuaty. Przeł. M. Betley. Warszawa: Świat Książki.

\section{SUMMARY}

The present-day Ojibway: Impressions from a trip to Canada

The purpose of this article is to share our impressions and experiences from the anthropological research focusing on the Ontario Ojibwa First Nation, which was our first expedition outside of Europe. We focused on the identity of this indigenous people, their culture preservation practices and processes of assimilation and Americanization taking place among the indigenous groups. Even though it is natural that changes occur, the question is: are those changes within the culture or against the culture? As it was merely our first approach to the field and the topic, the answers to those questions will be explored in detail during our next expeditions to the field.

Key words: Ojibway, Ontario, Canada, first research, impressions 